\title{
LICITANDO LO ILÍCITO. REFLEXIONES EN TORNO A LOS CASOS CCSS-FISCHEL E ICE-ALCATEL ${ }^{1}$
}

\section{LICITING THE ILLICIT. REFLECTIONS ON THE CCSS-FISCHEL AND ICE-ALCATEL CASES}

\author{
Fernando Artavia Araya*
}

RESUMEN

A partir de los escandalosos casos Caja Costarricense de Seguro Social (CCSS)-Fischel e Instituto Costarricense de Electricidad (ICE)-Alcatel, se reflexiona sobre las condiciones socio-institucionales que pueden facilitar la corrupción en las compras estatales de bienes y servicios al sector privado. Se intenta responder a tres preguntas centrales: ¿quiénes tomaron las principales decisiones?, ¿cómo decidieron? y ¿ante quiénes respondían por esas decisiones? Se concluye que un pequeño grupo de políticos y altos jerarcas públicos tomaron las decisiones más importantes sobre el destino de los multimillonarios contratos, $y$ ello con gran poder discrecional y de la forma más arbitraria, y burlando o evadiendo los mecanismos de control existentes en Costa Rica.

PALABRAS CLAVE: COSTA RICA * CORRUPCIÓN * CONTRATOS * FUNCIÓN PÚBLICA * SECTOR PRIVADO * SALUD * TELECOMUNICACIONES

\section{ABSTRACT}

Regarding the CCSS-Fischel and ICE-Alcatel skandals, the author reflects on the socioinstitutional conditions that may facilitate the corruption in the state buyings of goods and services to the private sector. The article is intended to answer three fundamental questions: Who made the main decisions? How were those decisions made? To whom were they accounted for? It is here concluded that a little group of politicians and high level public officers made the main decisions on the destiny of millionaire contracts, and that they did it with discrecional powers and in an arbitrarity way, avoiding the existing mechanisms of institutional and legal control in Costa Rica.

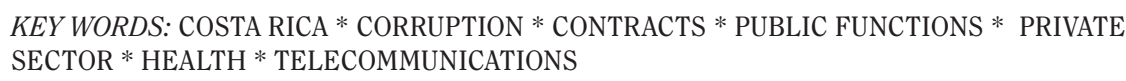

Escuela de Sociología de la Universidad de Costa Rica.

sociofe@hotmail.com

1 Este artículo está vinculado a otro anterior, al cual remito para un desarrollo más teórico sobre las condiciones que posibilitan la corrupción. Cfr. Artavia Araya, Fernando. "Decisiones públicas, beneficios privados. Consideraciones teóricas en torno a la corrupción". En: Revista de Ciencias Sociales 119. Universidad de Costa Rica, 2008: 13-26. Al igual que el referido artículo, el presente también es producto de una Beca Senior otorgada por el Instituto de Investigaciones Sociales de la Universidad de Costa Rica, al cual agradezco, y en especial a los(as) compañeros(as) del Programa de Política, Estado y Actores Políticos en Costa Rica. 


\section{BREVE PRESENTACIÓN DE LOS CASOS}

En el 2004, Costa Rica se vio sacudida por dos grandes escándalos de corrupción, a saber, los casos CCSS-Fischel e ICE-Alcatel, que vinieron a evidenciar el modus operandi con que grandes empresas proveedoras se aseguraban un resultado positivo en su concurso por la venta de bienes y servicios al Estado costarricense, mediante el pago de comisiones y "premios" a reconocidos políticos y altos jerarcas de dos de las más importantes instituciones públicas del país.

El caso ICE-Alcatel está relacionado con la adjudicación de 400000 líneas celulares GSM que, tras ganar un concurso a principios de 2001, el Instituto Costarricense de Electricidad (ICE) otorgó a esa firma francesa. Pero, fue hasta septiembre de 2004 que estalló el escándalo, al revelarse que dicha adjudicación había involucrado un importante tráfico de influencias $y$ dádivas al más alto nivel, en el cual se vieron involucrados no sólo miembros de la Junta Directiva del ICE $y$ otros funcionarios y técnicos de la institución, sino también dos expresidentes de la República, uno de los cuales debió renunciar a su puesto como Secretario General de la OEA, mientras el otro dimitió a su cargo de Director Ejecutivo del Foro Económico Mundial.

Por otra parte, el caso ccss-Fischel está vinculado al llamado "Proyecto Finlandia"2, un proyecto de Ley para contraer un préstamo con el gobierno finlandés destinado a la compra de equipo médico en el marco del Programa de Renovación del Sistema Hospitalario Nacional, y cuyo usuario final sería la Caja Costarricense del Seguro Social (CCSS). Se trataba de una línea de crédito blando, sin interés, a diez años plazo, $y$ con tres años de gracia, que el gobierno finlandés subvencionaría a cambio de que al menos el $50 \%$ del equipo médico fuera fabricado por empresas de su país. El proyecto fue aprobado en sólo tres días, y fue así como el Estado costarricense contrajo una deuda inicial de \$32 millones, que luego se amplió a $\$ 39,5$ millones. En el 2002, la licitación pública

2

Expediente nro. 14610.
LP-GDM-001-2002 para la compra del equipo médico fue adjudicada al consorcio finlandés Instrumentarium Medko Medical, representado en Costa Rica por Corporación Fischel. Pero, tras revelarse en abril de 2004 que la lujosa vivienda del Presidente Ejecutivo de la CCSS había sido comprada por el gerente financiero de Fischel, estalló el escándalo y sobrevino un aluvión de graves denuncias sobre comisiones $y$ "premios" recibidos por altos funcionarios de la institución e importantes figuras políticas, entre las que destacaba otro expresidente de la República.

Si bien el desenlace de los procesos judiciales aún está por decidirse, ello no impide proponer algunas reflexiones en torno a las condiciones que pudieron haber facilitado la corrupción en ambos casos. Para ello, trataremos de responder a tres preguntas fundamentales:

¿quiénes tomaron las principales decisiones? ¿cómo tomaron tales decisiones?

y ¿ante quiénes respondían por las decisiones asumidas? ${ }^{3}$

\section{CENTRALIZACIÓN EN LAS DECISIONES TOMADAS}

El acaparamiento de importantes decisiones en manos de un reducido grupo de políticos y servidores públicos, sobre todo cuando involucran la movilización de grandes cantidades de dinero y el poder para asignar un beneficio o un costo al sector privado, crea los primeros incentivos para el soborno y otras actuaciones ilícitas, en tanto las empresas o particulares podrían ofrecer dinero a cambio de la asignación de ese beneficio o costo, cuya magnitud

Estas preguntas surgen a partir del ya clásico trabajo de Robert J. Klitgaard, según el cual la corrupción se ve facilitada por tres condiciones fundamentales, a saber: a) la concentración en pocas personas de la toma de decisiones sobre el destino de cuantiosos recursos, b) el carácter discrecional con que son tomadas dichas decisiones, c) la falta de rendición de cuentas por las decisiones tomadas. Véase: Klitgaard, Robert. Controlling Corruption. University of California Press, Berkeley CA, 1988 . 
- dicho sea de paso- puede aumentar gracias al poder $y$ discrecionalidad de los funcionarios públicos, como bien señala Rose-Ackerman ${ }^{4}$. Claro ejemplo de ello es que, por iniciativa de la Junta Directiva de la CCSS, el "Préstamo Finlandés" sufrió una ampliación de $\$ 7,5$ millones, llevando a que la rebanada recibida por los políticos y funcionarios corruptos fuera aún más grande.

Ahora, para responder a la primera de nuestras preguntas arriba planteadas, debemos tomar en cuenta que en los casos bajo consideración estamos ante empresas que ganaron concursos para proveer de bienes y servicios a dos instituciones públicas costarricenses, el ICE y la CCSS, cuyo rasgo distintivo es que son autónomas ${ }^{5}$, lo cual condiciona el nivel a que se pudieron tomar las decisiones sobre los contratos en cuestión. La estructura administrativa de las instituciones autónomas se rige en lo fundamental por una Presidencia Ejecutiva, según Ley 5507, y por una Junta Directiva, cuya elección responde a un esquema conocido como 4-3, establecido desde 1970 por la Ley 4646. El problema se presenta porque ese tipo de estructura se presta para la politización de las instituciones autónomas, que terminan siendo tomadas como botín político de los diferentes gobiernos y su oposición, facilitándose así el amiguismo y el tráfico de influencias en relación, por ejemplo, con los contratos a empresas proveedoras. Dichos contratos, dependiendo de su monto, deben ser aprobados por la Junta Directiva de estas instituciones, según lo establece la Ley de Contratación Administrativa.

En el caso del ICE, a pesar de que también otros actores se vieron luego involucrados, entre ellos un ingeniero y el coordinador de la Comisión que supervisaba la ejecución del contrato, debe subrayarse que fue la Junta Directiva de la institución quien tomó la decisión final sobre la adjudicación a Alcatel por un monto de \$149 millones, así como un año atrás

Véase: Rose-Ackerman, Susan. "La economía política de la corrupción”. En: Ann Elliot, Kimberly. La corrupción en la economía global. México, Editorial Limusa/Grupo Noriega Editores, 2001:47-81. le había consignado otro contrato para ampliar las centrales de telefonía fija en todo el país por una suma de $\$ 109$ millones. Tres miembros de esa Junta Directiva aceptaron haber recibido "premios" por favorecer directamente a Alcatel, en coordinación con otras personalidades de gran peso político.

En el caso de la ccss, la elección de los miembros de su Junta Directiva es un poco más compleja, pues responde a un esquema de cuotas de representación, en que el Presidente Ejecutivo y otros dos representantes son designados por el Gobierno, tres por el sector empresarial (comercio, agrícola e industrial), y tres por los trabajadores (cooperativistas, sindicatos y solidaristas). Esos nueve integrantes constituían el máximo órgano de decisión respecto al destino de los recursos de la institución, y tenían la última palabra en cuanto a licitaciones $y$ contratos superiores a los $\$ 60$ millones. Pero, también existe un Concejo de Gerentes de la cCss, el cual está constituido por las gerencias de Operaciones, Administrativa, Pensiones, División Médica, División Financiera y la Gerencia de Modernización y Desarrollo. Esta última funcionó entre 1998 y el 2004, año en que fue cerrada precisamente a raíz del caso ccSS-Fischel. Durante los seis años transcurridos desde su creación, dicha gerencia fue dirigida por una misma persona, quien luego aceptó haber recibido parte de los $\$ 9,2$ millones en comisiones de Alcatel. A cargo de esa gerencia, que luego fue catalogada como una "estructura paralela" dentro de la CCSS, estaban las direcciones de Desarrollo Organizacional, de Planificación Corporativa, de Coordinación de Proyectos, de Desarrollo de la Salud y la subgerencia de Tecnologías de la Información, así como el manejo de millonarios créditos para construir y equipar hospitales.

Entonces, quienes tomaron las decisiones más determinantes en relación con el caso cCss-Fischel, era un grupúsculo de altos jerarcas de la institución, entre los que se encontraba el Presidente Ejecutivo y la Junta Directiva,

Véase la Constitución Política de la República de Costa Rica, Título XIV, Capítulo Único: Sobre las Instituciones Autónomas. 
y el Gerente de Modernización y Desarrollo. Pero, todo ello en complicidad con importantes figuras del gobierno y los partidos políticos tradicionales, quienes prestaron su cooperación y asesoría, o - por mejor decir- su influencia política, para allanar el camino del crédito finlandés, especialmente en su fase de aprobación legislativa. Pero, ¿quiénes participaron realmente en esa fase determinante del proceso? Las diversas acusaciones terminan apuntando en una misma dirección. El entonces jefe de fracción del Partido Unidad Social Cristiana (PUSC), fue quien más impulsó el proyecto en la Asamblea Legislativa en diciembre de 2001, así como quien realizó el lobby previo para que dicha iniciativa fuera enviada al Congreso, ante diferentes instancias y funcionarios, como el Presidente Ejecutivo de la ccss, la agregada comercial de Finlandia en Centroamérica, el Ministro de Salud, la Cancillería, la Oficina de Cooperación Internacional de Finlandia, entre otros. Una vez que el "Proyecto Finlandia" fue enviado a la Asamblea Legislativa, se encargó de realizar todo lo necesario para que fuera aprobado de la forma más expedita. Primero, presentó junto al jefe de fracción del Partido Liberación Nacional (PLN) una moción de dispensa de todos los trámites al proyecto ${ }^{6}$. Luego, presentó otra moción para alterar el orden del día, para que el "Proyecto Finlandia" se discutiera de primero ${ }^{7}, y$ finalmente, se encargó de presentar ante el plenario las supuestas bondades del proyecto, al cual calificaba como "un regalo". El proyecto de ley fue aprobado en el tiempo récord de sólo tres días, sin la más mínima discusión, y con la única objeción expresada por el diputado del minoritario y derechista partido Movimiento Libertario, quien tras solicitar un receso de 5 minutos para ojear el proyecto de casi cien páginas, anunció su voto en contra ${ }^{8}$.

$6 \quad$ Véase Acta de la Sesión nro. 105 del 10 de diciembre de 2001, p.8. Expediente nro. 14 610, p 64.

7 Véase Acta de la Sesión nro. 105 del 10 de diciembre de 2001, pp.46 y 47. Expediente nro. 14 610, pp.72 y 73 .

8 Véase Acta de la Sesión nro. 106 del 11 de diciembre de 2001, pp.85 y 86. Expediente nro. 14 610, pp. 84 y 85
Pues bien, con el cambio de gobierno en mayo de 2002, ese entusiasta impulsor del "Proyecto Finlandia" fue designado nuevo Presidente Ejecutivo de la CCSS, $y$ el resto es historia. De momento, queda patente cómo unas camarillas de altos jerarcas públicos y políticos de los dos partidos tradicionales, mediante sus decisiones e influencia, lograron inclinar la balanza para que Alcatel y Fischel, en representación de Instrumentarium, ganaran las multimillonarias licitaciones que hoy son motivo de zozobra. Pero, esto nos lleva a la segunda de nuestras preguntas: ¿cómo lo decidieron?, o formulado de otra manera, ¿atendiendo a cuáles criterios tomaron esas decisiones?

\section{ARBITRARIEDAD Y DISCRECIÓN EN LA TOMA DE DECISIONES}

El que un pequeño grupo de funcionarios decida sobre el destino de millonarios recursos públicos y jugosos contratos con el sector privado, no sería tan problemático si sus decisiones se dejaran orientar por reglas y criterios bien establecidos, que limitaran su margen de maniobra. Pero, debemos destacar de entrada que en Costa Rica existe una amplia legislación sobre la forma correcta en que se deben realizar las contrataciones estatales con el sector priva$\mathrm{do}^{9}$, a pesar de lo cual se producen casos como los aquí estudiados.

En el caso ICE-Alcatel, se siguieron prácticamente todos los pasos, procedimientos y trámites en diferentes instancias requeridos por la ley. A principios de 2001, el ICE publicó en diarios de circulación nacional la invitación a participar en el Procedimiento Abreviado nro. 1-2001, para el arrendamiento con opción de compra de 400000 líneas celulares GSM. Tras los análisis técnicos y financieros respectivos, la adjudicación recayó en la oferta que presentaron Alcatel y el Banco Centroamericano de Integración Económica (BCIE). Luego se

Para una valoración general y actual sobre el tema, véase: Donato, Claudio. Informe sobre la situación de la contratación administrativa en Costa Rica. Informe Final preparado para el XII Informe del Estado de la Nación. 
formalizó el respectivo contrato, y el ICE constituyó una comisión encargada de supervisar el adecuado proceso de instalación y puesta en operación de las 400000 líneas. En fin, desde un punto de vista puramente formal, no parecía haber prima facie nada ilícito en la contratación con Alcatel. Y, sin embargo, lo había. Pero, el problema no se encontraba en lo procedimental, sino más bien en la lógica que tras bambalinas inclinaba las decisiones de los altos funcionarios en uno u otro sentido. Según las declaraciones del exgerente de Alcatel-Costa Rica ante la Asamblea Legislativa y la Fiscalía, cada uno de los funcionarios y políticos involucrados establecía un porcentaje de entre un $1 \%$ $y$ un $1,5 \%$ de los contratos que ganara Alcatel, $y$ esos "premios" eran casi requisitos para concretar contrataciones con el ICE.

El caso ccss-Fischel, por su parte, muestra ciertas particularidades producto de las condiciones mismas en que se había acordado el crédito. Se trataba de un "préstamo amarrado", que imponía a la ccss, entre otras cosas, que al menos un 50\% del equipo fuera fabricado en Finlandia, que las ofertas fueran de $\$ 8$ millones o más, y que los fabricantes estuvieran inscritos en el Registro Nacional de Marcas y Patentes de Finlandia. Pero, ya desde el proceso de licitación algunas empresas proveedoras de equipo médico se quejaron de que la ley y el cartel imponían requisitos que solo podía cumplir el consorcio Instrumentarium Medko Medical. Incluso una de las empresas presentó un recurso de amparo contra el cartel que, según ella, lesionaba los derechos de otras firmas, al licitarse productos con especificaciones que correspondían exclusivamente a Instrumentarium. Aún así, el recurso fue declarado sin lugar por los magistrados, quienes parecían avalar con su voto los mecanismos de excepcionalidad con que se estaban violando algunos principios fundamentales de la contratación administrativa, como la igualdad de oportunidades y la sana competencia.

Pero, cabe preguntarse ¿cómo se determinaron las condiciones específicas del cartel?, ¿cómo se definió la lista de equipo hospitalario a licitar?, y finalmente si ¿respondían las decisiones tomadas a las necesidades reales de la ccss? El encargado de la Unidad Ejecutora del Proyecto Finlandia y el gerente de Modernización y Desarrollo de la ccss, decían desconocer cómo se había configurado la lista de los equipos licitados, pero aseguraban que las decisiones tomadas por ellos respondían a estudios técnicos de los asesores del proyecto. Ambos coincidían en justificar sus decisiones apelando a las recomendaciones de los asesores del proyecto. Pero, ¿qué tipo de asesoría era esa a que apuntaban?

El principal asesor encargado de elaborar los requisitos técnicos del cartel era un ingeniero que, meses antes de que el "Proyecto Finlandés" siquiera llegara a la Asamblea Legislativa, ya había viajado a Finlandia a visitar empresas fabricantes de equipos médicos, según -él y esto es lo inverosímil- por pura iniciativa personal y cubriendo sus propios gastos. Luego regresó al país, y medio año más tarde, fue contratado por la Unidad Ejecutora del Proyecto Finlandia. En aquella visita, este supuesto desinteresado ingeniero se había tomado la molestia de traer catálogos de los equipos médicos allí fabricados y que luego le sirvieron "como insumo" para definir la lista que apareció en el cartel, la cual no respondía a las necesidades reales de las clínicas y hospitales de la CCSS.

Un año antes de que el crédito finlandés llegara al Congreso, la Gerencia de Modernización y Desarrollo había solicitado a los directores de los centros hospitalarios de todo el país que enviaran una lista de sus necesidades prioritarias de equipo médico. Sin embargo, la mayoría de los requerimientos planteados por los directores nunca fueron atendidos, en tanto la compra debía limitarse estrictamente a la lista de los 22 tipos de equipos médicos ofrecidos por los finlandeses, entre los cuales ahora los directores tendrían que escoger. Fue así como se redefinieron las prioridades, llevando a que la CCSS no comprara según sus necesidades, sino según lo ofertado por los potenciales vendedores finlandeses.

Entre lo requerido por las diversas unidades hospitalarias y lo que se terminó licitando la brecha es abismal. Sólo por poner un ejemplo, los directores de los centros médicos habían pedido 12 máquinas de anestesia y se licitaron 
72, pidieron sólo una máquina de anestesia de alta tecnología y se licitaron 29. Ello motivó que la Comisión Técnica de Anestesistas manifestara su preocupación por la excesiva cantidad de esas costosas máquinas y sin estudios previos sobre su necesidad real. Hoy podemos entender el porqué de esa compra. La venta de máquinas de anestesia era precisamente la actividad más importante de Instrumentarium Medko Medical, pues constituía el 70\% de sus ventas netas, $y$ cuya fabricación era desarrollada por su empresa Datex Ohmeda, con plantas en Wisconsin y Colorado, no en Finlandia ${ }^{10}$.

Al final, con la ampliación del crédito se terminaron comprando 3037 aparatos, de los cuales una buena parte no eran necesarios, otros no podían ser instalados ni usados, $y$ otros más presentaron problemas de calidad. Según un estudio encargado por la Cancillería de Finlandia a la firma auditora Societé Generale de Surveillance (SGS), \$12 millones de los \$39,5 millones de la compra total (o sea, un 30\%) se utilizaron para comprar equipo innecesario. Un 23\% de los equipos adquiridos por la CCSS estaba en desuso, entre otras razones porque fueron reemplazados equipos a pesar de que funcionaban perfectamente, $y$ a veces los equipos recién adquiridos eran idénticos a los "viejos", algunos con sólo dos años de haberse comprado. Por otra parte, SGS concluyó que Instrumentarium sabía de antemano que ganaría el concurso, pues era el único consorcio en el mundo capaz de cumplir las condiciones del cartel, $y$ de ahí que no existiera ningún incentivo para ofrecer precios competitivos. El equipo de Instrumentarium resultó más caro que el ofrecido por otros dos oferentes, habiendo sobreprecios de entre un $28,5 \%$ y un $40 \%$, e incluso hasta un $80 \%$.

Las anomalías abundan y se pueden multiplicar los ejemplos, pero lo importante a destacar aquí es la forma arbitraria y el poder discrecional que prevaleció en las decisiones

10 Informe del Ing. Rafael Carrillo Lara al señor Presidente de la República Dr. Abel Pacheco de la Espriella. Comisión Investigadora de la CCSS. San José, agosto de 2004, p 25. tomadas por los agentes involucrados, así como el patrimonialismo que caracterizó sus actuaciones. Todo lo cual nos lleva a nuestra última pregunta: ¿ante quienes respondían por las decisiones tomadas?

\section{IRRESPETO A LOS CONTROLES Y FALTA DE RENDICIÓN DE CUENTAS}

Hemos visto que nuestra vulnerabilidad ante la corrupción es grande cuando el poder de decisión sobre importantes recursos y jugosos contratos con el sector privado se concentra en pocas manos, $y$ aumenta cuando quienes toman esas decisiones gozan de un amplio poder discrecional $y$ no se atienen a criterios bien definidos que delimiten sus actuaciones. Pues, esa vulnerabilidad es aún mayor cuando los agentes decisores parecen no responder ante nadie por sus acciones. Aludimos directamente al tema de la rendición de cuentas o accountability, que supone además la existencia de mecanismos de fiscalización y control sobre la actuación de los agentes públicos. Pero, es momento de responder, en relación con quienes tomaron las principales decisiones en los casos aquí estudiados, a nuestra tercera y última pregunta, ¿ante quiénes respondían por esas decisiones?

En Costa Rica existe una serie de instituciones y agencias cuya obligación es supervisar, prevenir, desalentar, promover la sanción, o sancionar acciones $\mathrm{u}$ omisiones presuntamente ilícitas de otras agencias estatales. Es decir, existen "agencias de accountability horizontal asignado" como las llama Guillermo O'Donnell11, tal y como la Contraloría General, la Fiscalía General, la Defensoría de los Habitantes, $y$ las diferentes auditorías internas de las instituciones públicas, entre otras. Pero, ¿qué sucedió con esos entes y mecanismos de control que se supone debieron haber evitado lo que de todas formas terminó ocurriendo? Como veremos de inmediato, el poder de esas agencias

11 Véase: O’Donnell, Guillermo. "Accountability Horizontal. La institucionalización legal de la desconfianza política". En: Isonomía 14, abril. 2001: 7-31. 
es muy relativo $y$ fue subestimado e ignorado por los agentes decisores.

En el caso ICE-Alcatel, al principio no parecía haber mayores inconvenientes, pero luego la División de Fiscalización Operativa y Evaluativa de la Contraloría señaló algunos problemas en cuanto a la fase de ejecución del contrato, sobre todo en relación con los plazos y la cobertura de la red, que había incidido negativamente en la comercialización de las líneas celulares por parte del ICE ${ }^{12}$. Pero, esos problemas, hay que insistir en ello, se detectaron en la fase de ejecución.

A diferencia de lo anterior, en el caso ccss-Fischel sí se dieron alertas desde diversos lugares a partir del proceso mismo de licitación, así como sobre la forma en que se utilizaría el dinero del crédito. Buena parte de los errores y vicios administrativos fueron señalados a través de múltiples investigaciones y oficios por los mecanismos de control interno de la institución. Se elaboraron 11 informes, en los cuales se advirtió la necesidad de hacer estudios de factibilidad legal, técnica, económica, social y financiera, con el fin de respaldar la decisión de ejecutar el "Préstamo Finlandia" y evitar el desperdicio de inversiones. La Auditoría Interna de la institución señaló controles inadecuados, subutilización de equipos, carencia de personal para operarlos, problemas de instalación e incumplimientos de garantía por parte de los proveedores de los equipos. Sin embargo, durante años todas esas recomendaciones fueron ignoradas, lo cual es muestra del desprecio de los agentes decisores por las recomendaciones y directrices de esas instancias fiscalizadoras, a pesar de la existencia de una Ley de Control Interno que obliga a atender sus señalamientos. También, lleva a que nos preguntemos si no existían otras formas más eficaces de hacerse escuchar ante otras instancias $y$ hacer públicas sus advertencias.

Véase el "Informe sobre algunos aspectos relativos al contrato suscrito por el ICE, para el arrendamiento con opción de compra de 400000 soluciones integrales telefónicas inalámbricas con la tecnología GSM", nro. DFOE-PR-18-2003 del 17 de diciembre de 2003.
Así mismo, el superintendente de servicios de salud aseguró que los jerarcas de la cCSS lo "arrinconaron" para callar estudios que mostraban las negativas opiniones de los asegurados. Según él, se produjo una "asfixia de los mecanismos de control y mordazas a los empleados" de la institución. Los incómodos informes de la Superintendencia de Servicios de Salud no eran del agrado del Presidente Ejecutivo y la Junta Directiva de la ccss, así que "fueron engavetados"13. Por su parte, el fiscal general aseguraba contar con reportes de amenazas a funcionarios que intentaron denunciar la corrupción al interior de la institución.

Ahora, una de las condiciones fundamentales que facilitó la corrupción en el caso cCSSFischel fueron los mecanismos de excepción para licitar, adjudicar y ejecutar el contrato, bajo el control de una Gerencia a la que se llegó a considerar "una república independiente", y una Unidad Ejecutora que actuaba como "estructura paralela". La figura de las "unidades ejecutoras" se convirtió en una de las formas favoritas para desarrollar en Costa Rica proyectos y programas de instituciones financieras internacionales, y se popularizó sobre todo a partir de los años noventa. Sin embargo, en tanto dichas unidades responden en cuanto a sus procedimientos administrativos a condiciones impuestas por la institución financiera o gobierno prestamista, el control sobre las mismas se dificulta, aunque se han tomado medidas tendientes a posibilitar una mayor fiscalización ${ }^{14}$.

En fin, aparte de la existencia de mecanismos de excepción que dificultan la fiscalización eficiente de algunos contratos con el sector privado, si una enseñanza debemos extraer, es la debilidad — que no inexistencia - de los mecanismos de control de que se dispone para

Véase: Rivera, Ernesto. Exsuperintendente de servicios de salud. Le pusieron una mordaza a la Caja. La Nación, 16/5/2004, p 4A.

Véase en el XI Informe del Estado de la Nación, el capítulo 7, intitulado "Ocho preguntas y respuestas sobre la corrupción política en Costa Rica". Programa Estado de la Nación, San José, 2005: pp.301-322, esp. p 312. 
hacer cumplir la ley, lo cual se ve agravado por la ausencia de una cultura política e institucional de rendición de cuentas en Costa Rica.

\section{REFLEXIONES FINALES}

Hemos intentado responder a las tres preguntas de ¿quiénes decidieron qué?, ¿cómo lo decidieron?, y ¿antes quiénes respondían por esas decisiones? Como hemos visto, un pequeño grupo de políticos y funcionarios de alto rango tenían el poder de tomar las decisiones más importantes sobre el destino de cuantiosos recursos, relacionados con multimillonarios contratos con grandes empresas extranjeras, ello de la forma más arbitraria e irresponsable, $y$ burlando o evadiendo los mecanismos de control existentes.

Se trata de dos casos que, si bien mantienen ciertas semejanzas, difieren fundamentalmente en cuanto a su nivel de complejidad. El caso CCSS-Fischel involucró una serie de fases y procedimientos (aprobación de un acuerdo de cooperación entre dos gobiernos, tramitación de un proyecto de ley, ampliación del crédito inicial, entre otras) que requerían del concurso de muchas otras personas fuera de la institución y hasta del país. Si bien el caso ICE-Alcatel también muestra un alto grado de elaboración, a riesgo de parecer simplista, se puede decir que con todo y todo se trató de un caso típico de soborno a funcionarios públicos, con el agravante por supuesto de que participaron importantes figuras políticas. Ahora, también en cuanto a la forma en que se tomaron esas decisiones hay marcadas diferencias, aunque el fin último era más o menos el mismo: obtener beneficios privados extraposicionales de parte de las compañías proveedoras.
Como hemos visto, los acusados de corrupción en ambos casos recibieron "premios" o comisiones por ayudar a que se otorgaran contratos a empresas extranjeras para la compra de bienes y servicios por parte del Estado costarricense. Se trata de casos de contratación administrativa, para lo cual Costa Rica cuenta con toda una normativa y una serie de controles institucionales, que se supone debieron haber evitado lo que sucedió. De ahí, la importancia de reforzar los mecanismos de fiscalización realmente, pues de lo contrario es grande el riesgo de que se vuelvan a presentar situaciones similares a las estudiadas. También, deberían ser implementados mecanismos de control cruzado, donde no solamente las agencias estatales e internas de fiscalización, sino también con la participación de otras empresas concursantes y la misma ciudadanía, se pudieran advertir y corregir a tiempo las irregularidades que se puedan presentar. Todo lo cual requeriría de un sistema transparente de información sobre la contratación administrativa, donde se publique en sus detalles quiénes, cómo, bajo qué criterios y porqué se toman las decisiones. Y ello implicaría la promoción de una cultura política e institucional de rendición de cuentas, algo en lo cual existe un verdadero déficit en el país.

La vulnerabilidad ante la corrupción en importantes licitaciones públicas se podrá disminuir, si bien no eliminar, en tanto se amplíe la participación de otros actores sociales en la toma de decisiones. Esta participación deberá ser tomada de manera no arbitraria siguiendo criterios previamente establecidos. Sumado a lo anterior, es importante generar un control, tanto por parte de las instancias fiscalizadoras fuertes, como por una ciudadanía activa y vigilante. 